\title{
Surgeons preference for lumbar disk surgery: a discrete choice experiment
}

\author{
Pravesh S. Gadjradj ${ }^{1}$ (C) - Biswadjiet S. Harhangi ${ }^{2} \cdot$ Maurits W. van Tulder $^{3} \cdot$ Wilco C. Peul $^{4} \cdot$ Esther W. de Bekker-Grob $^{5,6}$
}

Received: 13 January 2021 / Accepted: 3 April 2021 / Published online: 19 April 2021

(c) The Author(s) 2021

\begin{abstract}
Purpose Multiple surgical techniques are practiced to treat sciatica caused by lumbar disk herniation. It is unknown which factors surgeons find important when offering certain surgical techniques. The objective of this study is threefold: 1) determine the relative weight surgeons place on various characteristics of sciatica treatment, 2) determine the trade-offs surgeons make between these characteristics and 3) identify preference heterogeneity for sciatica treatment.

Methods A discrete choice experiment was conducted among members of two international neurosurgical organizations. Surgeons were asked on their preferences for surgical techniques using specific scenarios based on five characteristics: effectiveness on leg pain, risk of recurrent disk herniation, duration of postoperative back pain, risk of complications and recovery period.

Results Six-hundred and forty-one questionnaires were filled in, the majority by neurosurgeons. All characteristics significantly influenced the preferences of the respondents. Overall, the risk of complications was the most important characteristic in the decision to opt-in or opt-out for surgery (35.7\%). Risk of recurrent disk herniation (19.6\%), effectiveness on leg pain (18.8\%), postoperative back pain duration (13.5\%) and length of recovery period (12.4\%) followed. Four latent classes were identified, which was partly explained by the tenure of the surgeon. Surgeons were willing to trade-off $57.8 \%$ of effectiveness on leg pain to offer a treatment that has a $1 \%$ complication risk instead of $10 \%$.

Conclusion In the context of this discrete choice experiment, it is shown that neurosurgeons consider the risk of complications as most important when a surgical technique is offered to treat sciatica, while the risk of recurrent disk herniation and effectiveness are also important factors. Neurosurgeons were prepared to trade off substantial amounts of effectiveness to achieve lower complication rates.
\end{abstract}

Keywords Lumbar disk herniation · Preferences · Discrete choice experiment

Pravesh S. Gadjradj

p.gadjradj@erasmusmc.nl

1 Department of Neurosurgery, Park MC, Hoofdweg 90, Rotterdam, the Netherlands

2 Department of Neurosurgery, Erasmus MC: University Medical Center Rotterdam, Rotterdam, the Netherlands

3 Department Movement Sciences, Faculty Behavioral and Movement Sciences and, Amsterdam Movement Science Research Institute, Vrije Universiteit, Amsterdam, the Netherlands

4 Department of Neurosurgery, Leiden University Medical Center, Leiden, the Netherlands

5 Erasmus Choice Modelling Centre, Erasmus University Rotterdam, Rotterdam, the Netherlands

6 Erasmus School of Health Policy and Management, Erasmus University Rotterdam, Rotterdam, the Netherlands
Abbreviations

$\begin{array}{ll}\text { LDH } & \begin{array}{l}\text { Lumbar disk herniation } \\ \text { OM }\end{array} \\ \text { OptED } & \begin{array}{l}\text { Pen microdiscectomy } \\ \text { discectomy }\end{array} \\ \text { DCE } & \text { Discrete choice experiment } \\ \text { EANS } & \text { European Association of Neurosurgical Societies } \\ \text { CNS } & \text { Congress of Neurological Surgeons }\end{array}$

\section{Introduction}

The natural course of sciatica caused by lumbar disk herniation (LDH) is favorable, and the majority of cases in the general population resolve with conservative care. Surgery, however, is recommended in patients whose symptoms are persistent despite conservative care $[1,2]$. 
In 1909, the first report on the surgical treatment of LDH was published [3]. Due to invention and technical innovation, the surgical technique has been modified to conventional open microdiscectomy $(\mathrm{OM})$ that is currently regarded as the golden standard procedure $[4,5]$. Due to further developments such as the introduction of the endoscope to the surgical field, other techniques for performing lumbar discectomy were introduced such as tubular discectomy and percutaneous transforaminal endoscopic discectomy (PTED) [6].

Based on pooled results from previous comparative studies, clinical outcomes of tubular discectomy are largely equivalent to those of OM. Furthermore, full-endoscopic procedures may be associated with significantly improved clinical outcomes, e.g., blood loss, durotomies, length of hospital stay and leg pain, as compared to conventional OM [7]. The differences of these outcomes between surgical techniques, however, may be small and not clinically important. Because of these ambiguous results, it is unclear whether any of these techniques have clear benefits over the other.

Currently, it is unknown based on which features, surgeons decide what surgical techniques they offer patients. For instance, patients who undergo PTED have shorter hospitalization duration compared to patients who undergo OM, but at the same time they may be more at risk to undergo revision surgery [8]. This trade-off between duration of hospitalization and a potential higher risk for revision surgery makes it difficult for policy makers and surgeons to decide which technique to offer patients. Previous research did not evaluate surgeons' preferences in offering lumbar disk surgery beyond efficacy and safety and did not measure the acceptable trade-offs of risk and benefits of different surgical techniques. The goal of the current study is threefold: 1) to determine the relative weight that surgeons place on various characteristics of lumbar disk herniation treatment, 2) to determine the trade-offs surgeons make between these characteristics and 3) to identify preference heterogeneity among surgeons for lumbar disk herniation treatment.

\section{Methods}

\section{Discrete choice experiment}

To elucidate and quantify preferences for offering a surgical procedure among neurosurgeons, a discrete choice experiment (DCE) was developed. DCEs are increasingly advocated in health care studies to quantify preferences [9]. A DCE is a survey method which is based on the concept that when choices are made for interventions, characteristics of the interventions are weighted off next to each other. An example of a choice set is given in Fig. 1. Respondents are asked to choose for surgical treatment "A," treatment "B" or to opt-out. In a DCE, respondents are offered multiple choice sets in which the levels of the characteristics are variable [10].

\section{Study design}

By means of a literature search, a list of characteristics and matching levels was made [11, 12]. Based on interviews of patients at the outpatient clinic and on further consensus of the research group existing of a neurosurgeon, a researcher and a physician specialized in the care of patients with musculoskeletal disorders, a final selection of characteristics and

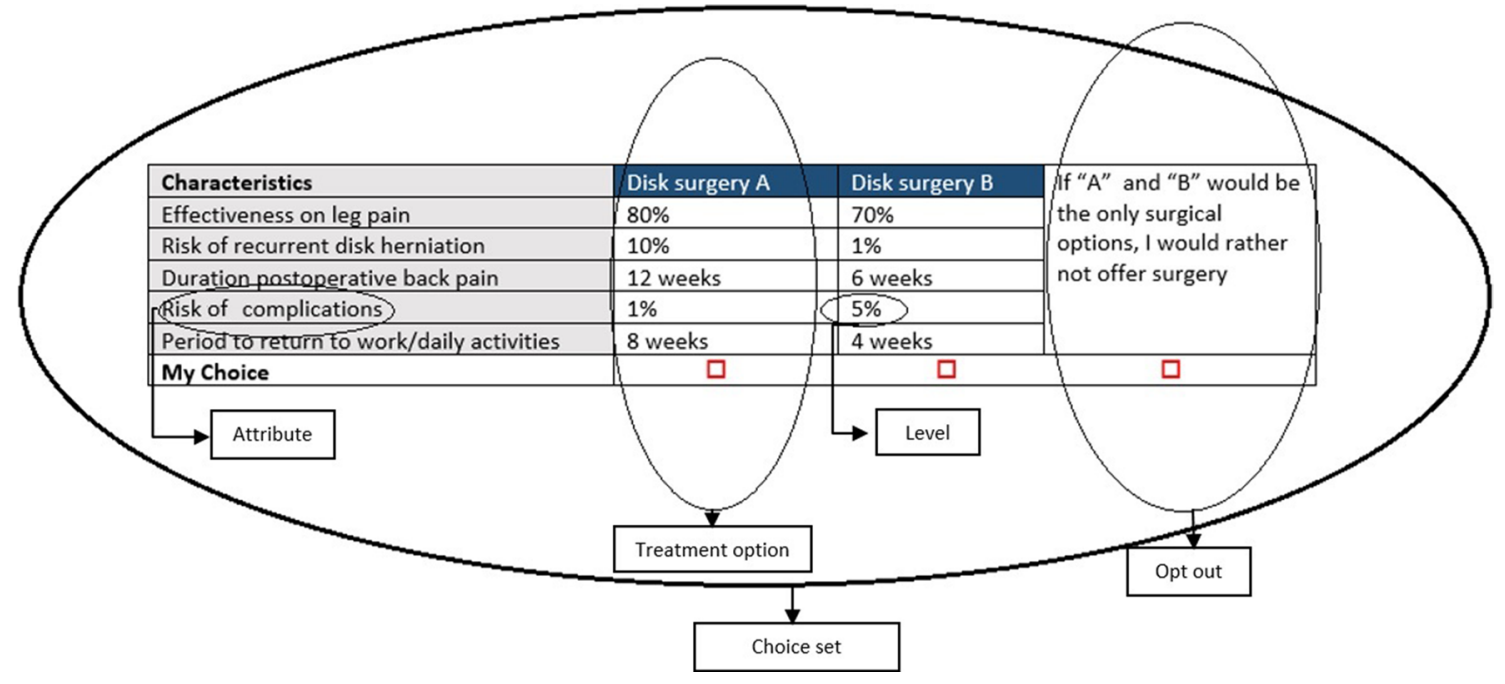

Fig. 1 An example of a choice set of the discrete choice experiment 
Table 1 Characteristics and levels of the surgical options used in the DCE

\begin{tabular}{ll}
\hline Characteristics & Levels \\
\hline Effectiveness on leg pain & $70 \%$ \\
The reduction of leg pain after surgery & $80 \%$ \\
& $90 \%$ \\
Risk of recurrent disk herniation & $1 \%$ \\
The risk of recurrent disk herniation within one year requiring surgery & $5 \%$ \\
& $10 \%$ \\
Duration of postoperative back pain & 1 week \\
& 6 weeks \\
Risk of complications & 12 weeks \\
The overall complication risk, taking into account nerve root injury, dural tear, wound infection, & $1 \%$ \\
etc. & $5 \%$ \\
Recovery period & $10 \%$ \\
Period to return to work/daily activities & 1 week \\
& 4 weeks \\
\end{tabular}

levels was made (see Table 1). These characteristics were chosen because they represent core outcomes of lumbar spine surgery. The characteristics of the surgical procedure included are (1) the effectiveness on leg pain, (2) the risk of recurrent disk herniation, (3) the duration of postoperative back pain, (4) the risk of complications and (5) the recovery period. An opt-out option was also added because-as in real-life lumbar discectomy for sciatica is usually an elective procedure. Levels were chosen based on expert opinion and on the literature [12-14]. The characteristics and levels produce $243\left(3^{5}\right)$ possible treatment profiles. Because testing of 243 treatment profiles comes with a large burden to the respondents; a Bayesian efficient DCE was produced (Ngene software version 1.1.; Choice metrics, Sydney, Australia) to be able to estimate the parameters of interest in an efficient way, while taking respondent burden into account. The efficient design contained 24 choice sets divided over two survey versions. Hence, each respondent filled out 12 choice sets.

To pilot test the survey, it was distributed among neurosurgeons that were affiliated with the national Netherlands Society of Neurosurgery. Based on the 39 surveys received and following best practice, the 24 choice sets divided among two survey versions were further optimized [15]. The final survey consisted out of three parts: (1) demographics of the respondents; (2) opinions on what makes a surgical technique to treat LDH "minimally invasive"; and (3) 12 choice sets, alternating per version. Based on a rule of thumb, at least 63 respondents were needed to adequately perform analyses $[16,17]$.

\section{Study setting and population}

The final survey was distributed to members of the European Association of Neurosurgical Societies (EANS) and members of the Congress of Neurological Surgeons (CNS), using SurveyMonkey. Both the EANS and the CNS are international professional organizations representing neurosurgeons worldwide. While the EANS is more focused on European neurosurgeons, the CNS is more focused on neurosurgeons from the USA. After initial distribution of the survey, reminders were sent after one and two months to increase the response rate. Because no patients were involved in this study, the institutional review board waived the need for medical ethical approval.

\section{Statistical analysis}

Demographics and opinions of respondents were analyzed using descriptive analyses using SPSS version 25.0 (IBM Corp. NY, USA). Valid percentages were used to present the data. Using NLogit 4.0 software (Econometric Software, NY, USA), panel latent class logit model was estimated [18]. This form of logistic regression analysis can take preference heterogeneity into account by identifying groups (latent classes) of respondents with similar treatment preference patterns. In order to determine the number of classes, we selected the model with the best fit based on the BIC criterion. We tested a number of different specifications for the utility function (e.g., categorical or numerical attribute levels and two-way interactions between attributes). The optimal utility function was: 


$$
\begin{aligned}
V_{n s j \mid c}= & \beta_{0 \mid c}+\beta_{1 \mid c} \text { effectiveness }{ }_{n s j \mid c}+\beta_{2 \mid c} \text { risk of recurrence }(5 \%)_{n s j \mid c} \\
& +\beta_{3 \mid c} \text { risk of recurrence }(10 \%)_{n s j \mid c} \beta_{4 \mid c} \text { duration of back pain }(6 \mathrm{wks})_{n s j \mid c} \\
& +\beta_{5 \mid c} \text { duration of back pain }(12 \mathrm{wks})_{n s j \mid c}+\beta_{6 \mid c} \text { complication risk }(5 \%)_{n s j \mid c} \\
& +\beta_{7 \mid c} \text { complication } \operatorname{risk}(10 \%)_{n s j \mid c}+\beta_{8 \mid c} \text { recovery period }(4 w k s)_{n s j \mid c} \\
& +\beta_{9 \mid c} \text { recovery period }(12 \mathrm{wks})_{n s j \mid c}
\end{aligned}
$$

where $V_{n s j l c}$ represent the observable utility that respondent $n$ belonging to class segment $c$ has for alternative $j$ in choice set $s ; \beta_{0 \mid c}$ represents an alternative specific constant for a certain class; and. $\beta_{1-9 \mid c}$ are class specific parameter weights (coefficients) associated with each attribute (level) of the DCE

In addition to the utility function, the final model allowed for one covariate (surgeon's tenure) to enter into the class assignment model. The class assignment utility function for the final model was:

$V_{n c}=\beta_{0 c}+\beta_{1 c}$ tenure $_{n}$

Only effectiveness on leg pain acted as linear characteristic. Coefficients, also known as class-specific parameter weights, associated with each characteristic were calculated. A coefficient with a $p$ value $\leq 0.05$ indicated statistical significance of a characteristic level and therefore importance of a characteristic in the decision to opt-in or opt-out for surgical treatment. A covariate with a $p$ value $\leq 0.05$ indicated that that covariate can distinguish between different classes. A positive coefficient means that the characteristic has a positive effect on the preference of a treatment, while a negative coefficient has an adverse negative effect on the preference of a treatment. The value of the coefficient also indicates the importance of characteristics.

In addition to this, the ranking of the importance scores of all characteristics were determined [9]. The ranking was made per latent class with " 1 " ranking the most important characteristic and " 5 " the least important characteristic. Furthermore, the coefficients were translated to calculate clinically relevant trade-offs. In this way, we can estimate whether surgeons were willing to trade off effectiveness on leg pain in order to shorten the duration of postoperative back pain, decrease the risk of complications, decrease the risk of recurrent disk herniation or shorten the recovery period. Hereto the ratio of one of the coefficients of these last four characteristics was taken as nominator and with effectiveness on leg pain as the denominator.

\section{Results}

\section{Demographics}

The final survey was filled in by 602 respondents. The 39 responses that were used to pilot test the DCE design were added to these responses. Of all the responses, 16
Table 2 Demographics of the respondents

\begin{tabular}{llll}
\hline & $\mathrm{N}(\%)$ & & $\mathrm{N}(\%)$ \\
\hline Gender & 641 & Years in clinical practice & 636 \\
Male & $599(93.4 \%)$ & $\leq 5$ years & $117(18.4 \%)$ \\
Female & $42(6.6 \%)$ & $6-10$ years & $134(21.1 \%)$ \\
& & $11-20$ years & $177(27.8 \%)$ \\
Function & 639 & $>20$ years & $208(32.7 \%)$ \\
Neurosurgeon & $581(90.9 \%)$ & & \\
Neurosurgeon in training & $57(8.9 \%)$ & Continent & 641 \\
Orthopedic surgeon & $1(0.16 \%)$ & Africa & $11(1.7 \%)$ \\
& & Asia and Oceania & $58(9.0 \%)$ \\
Amount of lumbar disk surgeries & 637 & Europe & $96(15.0 \%)$ \\
performed annually & & North America & $443(69.1 \%)$ \\
$\leq 50$ & $304(47.7 \%)$ & South America & $33(5.1 \%)$ \\
$51-100$ & $183(28.7 \%)$ & & \\
$101-200$ & $117(18.4 \%)$ & & \\
$>200$ & $33(5.2 \%)$ & & \\
\hline
\end{tabular}




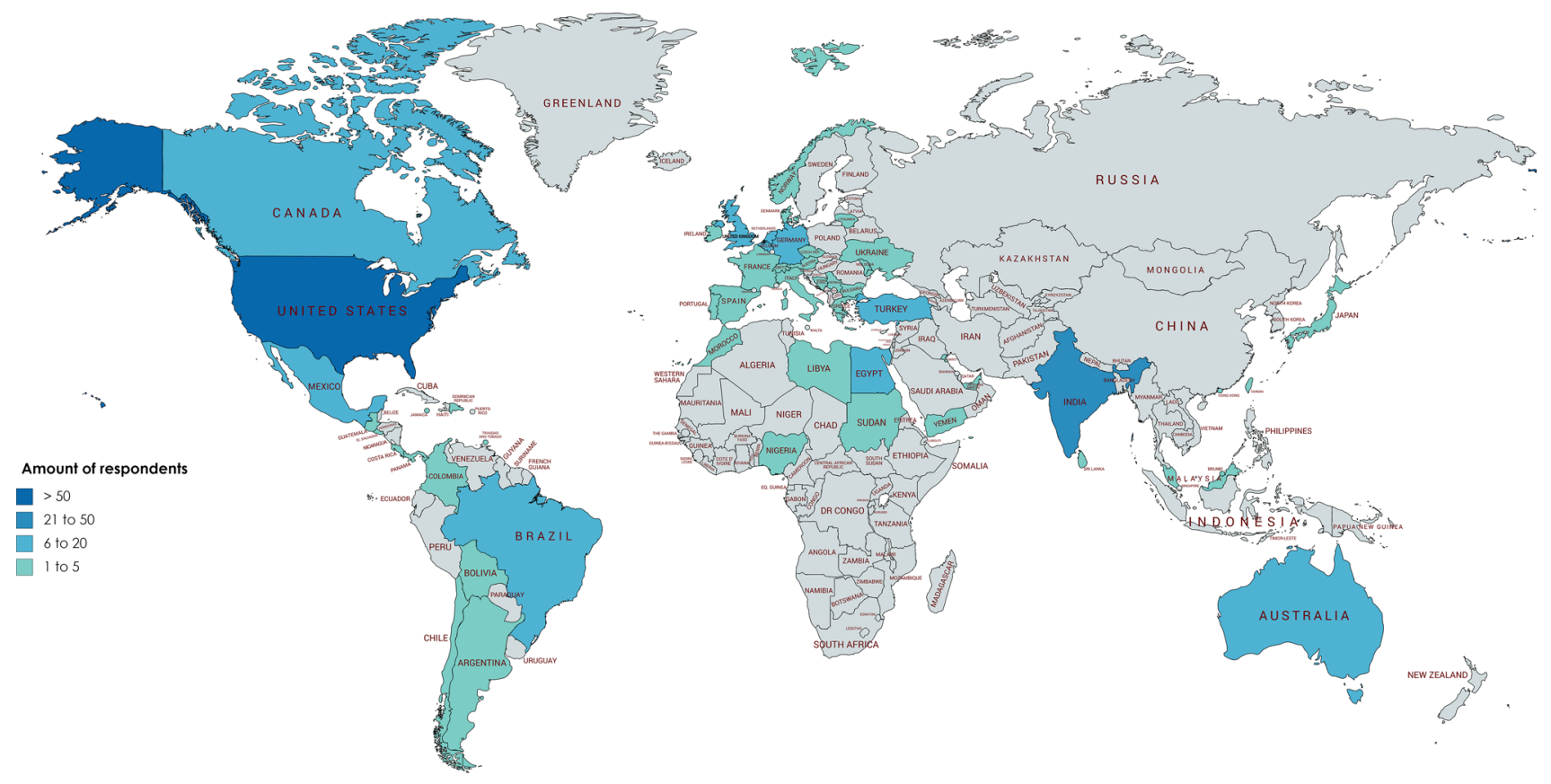

Fig. 2 A geographic overview of the working locations of the respondents

Able to perform the technique on outpatient basis

Ability to resume work and daily activities early

Small size of the scar

Low rate of postoperative back pain

Low risk of recurrent disk herniation

Low complication risk

Limited amount of damage to tissue

Effectiveness on radiculair pain

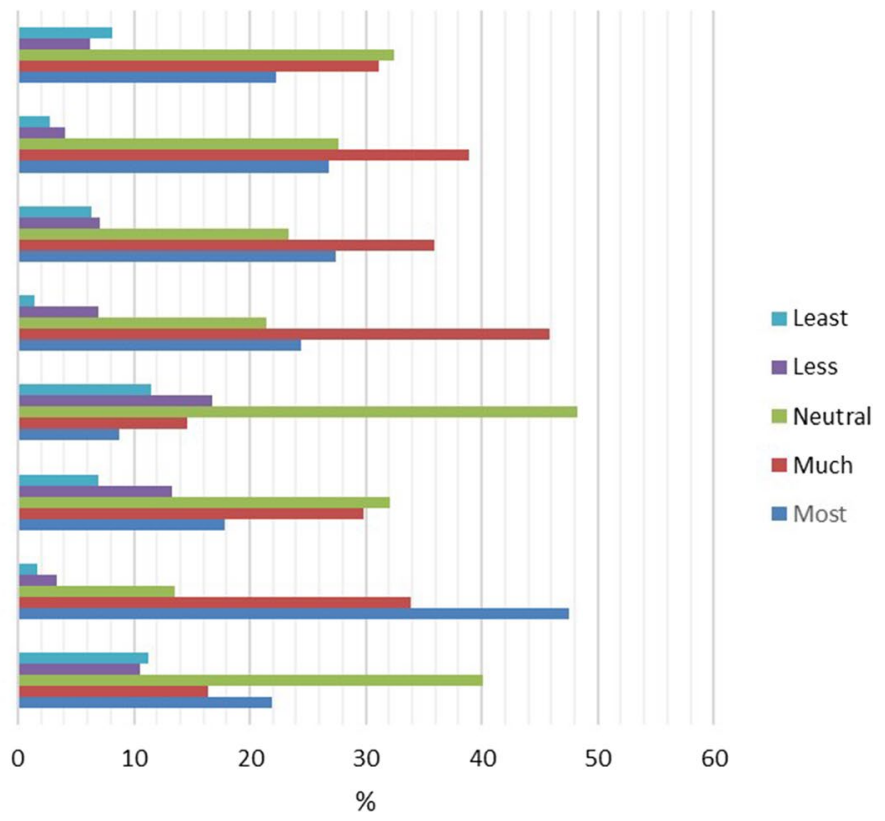

Fig. 3 What makes a surgical technique for lumbar discectomy minimally invasive?

had no answers on the DCE choice sets leading to 625 responses for the DCE analyses. Demographics of the respondents are depicted in Table 2, while Fig. 2 gives an overview of the respondents working locations. 581 out of the $638(91.1 \%)$ respondents were neurosurgeons and mean tenure was $17.0( \pm 11.8 \mathrm{SD})$ years. All respondents performed an annual mean of $85( \pm 74.5 \mathrm{SD})$ procedures for $\mathrm{LDH}$. 


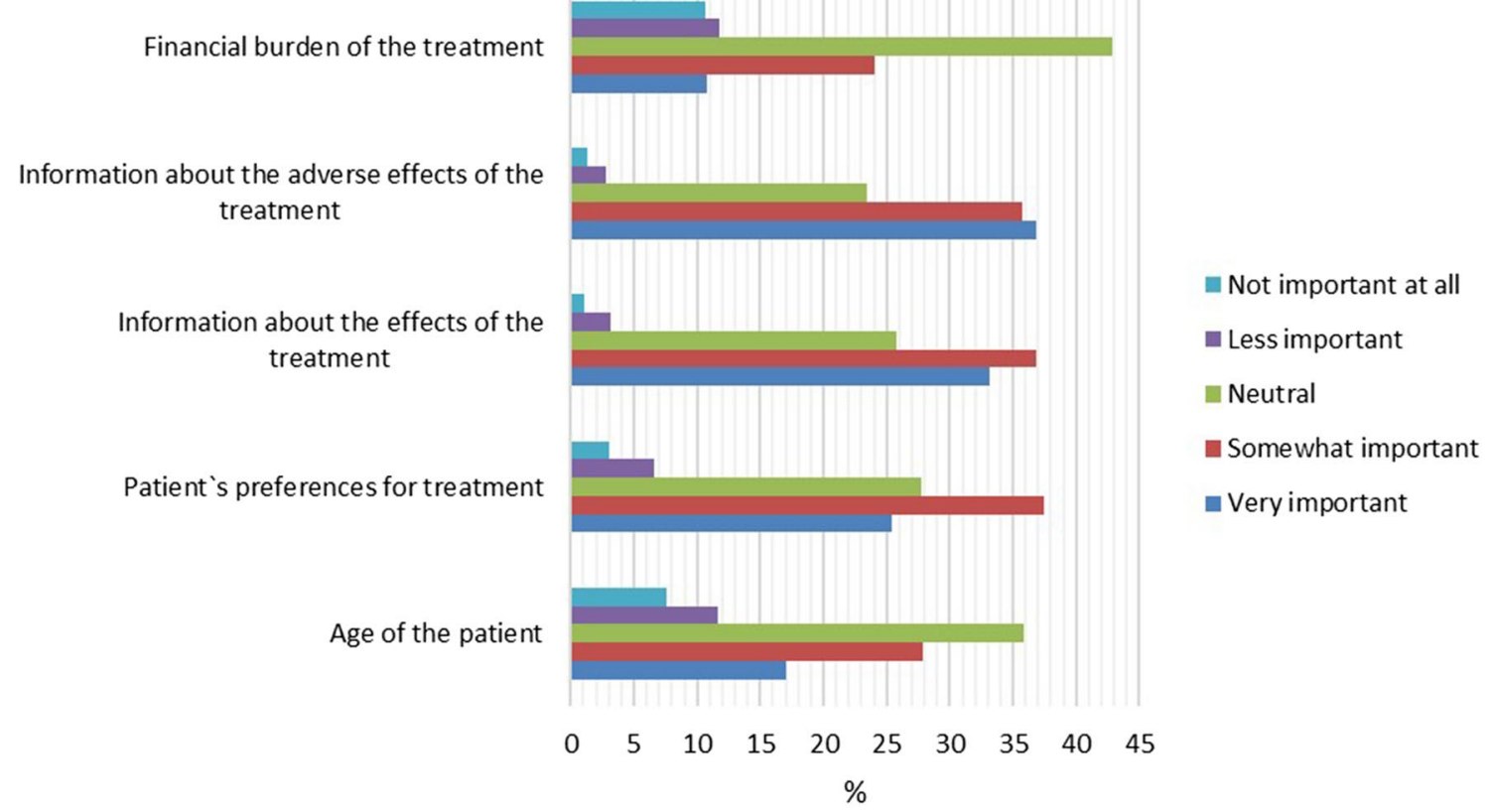

Fig. 4 Factors that influence the type of surgery is offered to patients

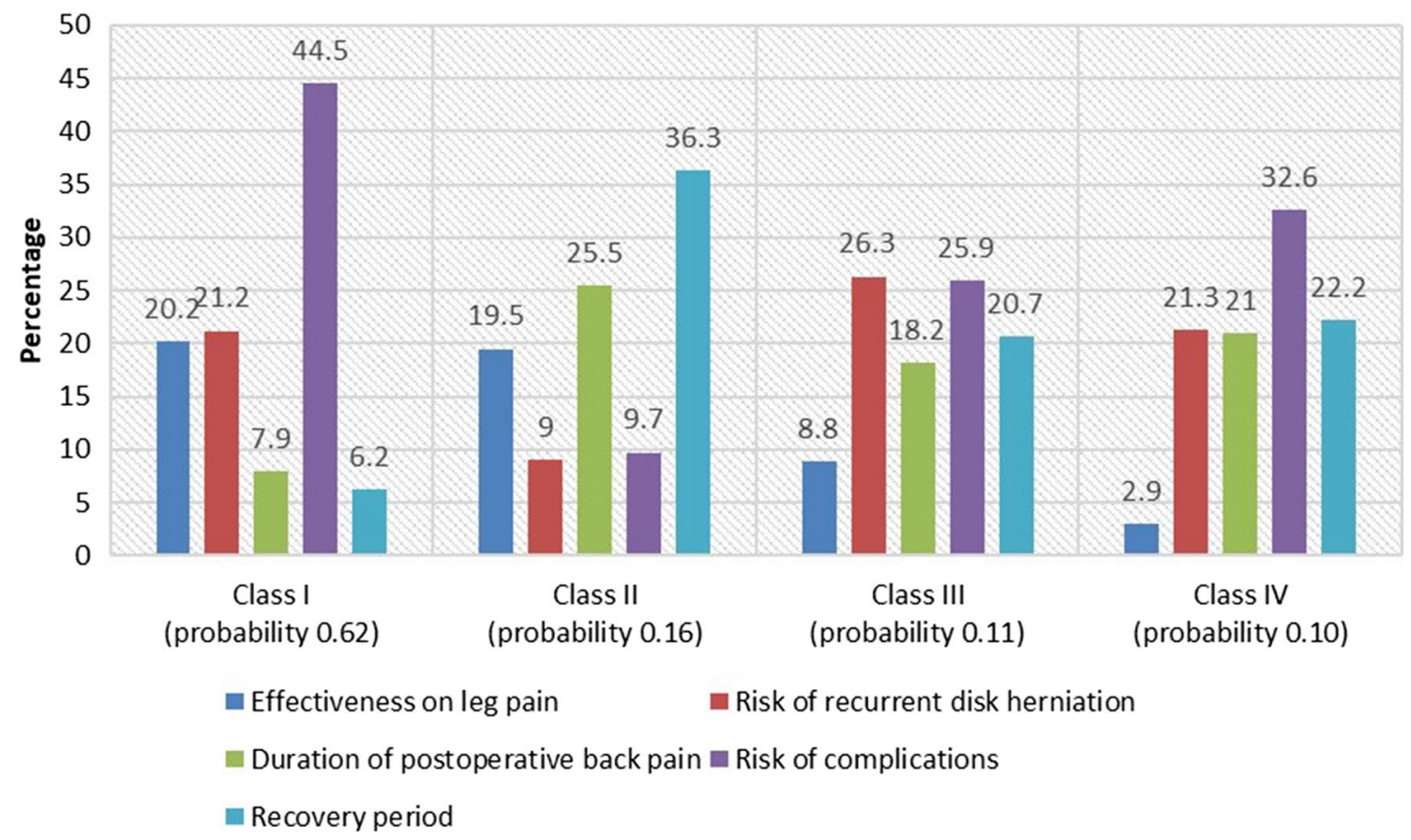

Fig. 5 Comparison of relative importance of characteristics of lumbar disk surgery between latent classes

\section{Opinions on what makes a surgical technique "minimally invasive"}

The importance of characteristics of minimally invasive surgery is depicted in Fig. 3. A limited amount of damage to tissue was most important (47.5\%) followed by a small scar size (27.4\%), early resumption of work and daily activities (26.8\%) and a low rate of postoperative back pain (24.4\%). A low rate of recurrent disk herniation, effectiveness on radicular pain and a low complication risk were deemed 
less important. When multiple surgical techniques are available to treat $\mathrm{LDH}$, the importance of factors influencing the procedure offered is presented in Fig. 4. Information on the effects $(33.2 \%)$ and adverse effects $(36.8 \%)$ were most important in the decision making, while financial burden of the treatment and age of the patient were of less importance.

\section{Latent classes}

Based on the latent class analyses, four groups of preference patterns could be identified (see Fig. 5):

- Class I with a $62 \%$ probability of respondents belonging to this class. This class was characterized by surgeons who thought that the risk of complications was of the most importance $(44.5 \%)$ in their treatment decision, followed by the recurrence rate $(21.2 \%)$, the effectiveness $(20.2 \%)$, the postoperative back pain duration $(7.9 \%)$ and the recovery period $(6.2 \%)$.

- Class II (probability of $16 \%$ ): the recovery period was of most importance (36.3\%) followed by the postoperative back pain duration $(25.5 \%)$, the effectiveness $(19.5 \%)$, the risk of complications $(9.7 \%)$ and the risk of recurrence $(9 \%)$.

- Class III (probability of 11\%): recurrence risk (26.3\%) and risk of complications (25.9\%) were seen as most important, followed by the recovery period (20.7\%), the postoperative back pain duration $(18.2 \%)$ and the recovery period $(8.8 \%)$.

- Class IV(probability of 10\%): risk of complications was most important (32.6\%) followed by the recovery period (22.2\%), the risk of recurrent disk herniation (21.3\%), the postoperative back pain duration $(21.0 \%)$ and effectiveness $(2.9 \%)$.

Where the risk of complications mainly decided the preferences of class I and IV, the recovery period and the risk of recurrent disk herniation mainly decided the preference of class II and III, respectively. Of all demographics tested, only tenure was significantly associated with belonging to class I $(p=0.009)$. Gender, function, amount of annually performed discectomies and continent of employment were all not associated with any of the latent classes.

Almost all coefficients proved to significantly influence preferences (see supplementary Table 1). A surgical technique to treat LDH was more preferred if it had a higher effectiveness on leg pain, had less risk of recurrent $\mathrm{LDH}$, had a shorter duration of postoperative back pain, less complication risk and a shorter recovery period.

\section{Importance score}

Overall, the complication rate determined the preference of surgeons for a surgical procedure for $35 \%$. Risk of recurrent disk herniation (19.6\%), effectiveness on leg pain $(18.8 \%)$, postoperative back pain duration (13.5\%) and recovery period (12.4\%) followed. The importance scores of the characteristics in decision making of the four latent classes were also calculated and are shown in Fig. 5.

\section{Trade-offs}

Trade-offs that surgeons are willing to make with effectiveness on leg pain are presented in Table 3. For instance, surgeons were willing to trade-off $58 \%$ of effectiveness in leg pain to offer a treatment that has a $1 \%$ complication risk instead of $10 \%$. Furthermore, surgeons were willing to trade-off $32 \%$ of effectiveness to offer a treatment that has a 1-week recovery period compared to 12 weeks and $31 \%$ of effectiveness to offer a treatment that has a $1 \%$ recurrence risk compared to $10 \%$.

\section{Discussion}

This study presents the results of a DCE among 625 surgeons, mostly neurosurgeons, employed at all continents. All surgical treatment characteristics that were tested in

Table 3 Results of the linear trade-offs respondents were willing to make

\begin{tabular}{lcl}
\hline Characteristics & $\begin{array}{c}\text { The respondent is willing to trade-off } \\
(\ldots \%) \text { effectiveness in leg pain }\end{array}$ & .. to offer a treatment that \\
\hline Risk of recurrent disk herniation & 0.7 & $\ldots$ has a $1 \%$ risk of recurrence compared to $5 \%$ \\
& 30.6 & $\ldots$ has a $1 \%$ risk of recurrence compared to $10 \%$ \\
Duration of postoperative back pain & 19.1 & $\ldots$ has a 1-week duration of low back pain instead of 6 weeks \\
& 28.7 & $\ldots$ has a 1-week duration of low back pain instead of 12 weeks \\
Risk of complications & 21.8 & $\ldots$ has a 1\% risk of complications compared to $5 \%$ \\
Recovery period & 57.8 & $\ldots .8$ has a 1\% risk of complications compared to $10 \%$ \\
& 31.6 & $\ldots$ has a 1-week recovery period compared to 4 weeks
\end{tabular}


the DCE significantly influenced the preferences of the respondents. Overall, surgeons considered the risk of complications the most important characteristic. Risk of recurrent disk herniation, effectiveness on leg pain, postoperative back pain duration and length of recovery period were also considered important. Based on substantial heterogeneity in preferences, four latent classes were identified. Rather than complication risk, the risk of recurrent disk herniation and the recovery period were deemed most important in two of these latent classes. Surgeons with a longer tenure were significantly represented in latent class I, in which the risk of complications was most important and the recovery period less. Overall, surgeons were willing to trade-off more than half of effectiveness on leg pain to offer a treatment that has a $1 \%$ complication risk instead of $10 \%$.

"Primun non nocere" which is translated from Latin as "first, do no harm," is a fundamental principle in Medicine which is underlined by the preferences of the surgeons included in this study. By $35.7 \%$, the risk of complications was considered to be the most important characteristic to opt-in or opt-out for surgery for sciatica. Nowadays, lumbar discectomy is considered to be a safe and effective procedure with low rates of serious adverse events[19]. Previous research comparing conventional open microdiscectomy with tubular discectomy or with full-endoscopic discectomy shows no statically or clinically relevant differences in complications between these different techniques. Nevertheless, the hypothetical situation to offer a procedure which has a $4 \%$ or $9 \%$ higher complication rate than another procedure raises considerable resistance for surgeons emphasized by surgeons being prepared to trade off up to $57.8 \%$ of effectiveness to achieve lower complications rates.

Strengths of the study include the large amount of responses received and the mixed method approach used. Some limitations, however, have to be acknowledged. One may be that only clinical characteristics were taken into account. Factors such as financial factors or the difficulty of mastering a surgical technique were not applied in this DCE. For instance, partially due to a limited view through an endoscope, PTED might be more difficult to master for surgeons compared to conventional OM [14, 20]. Therefore, only a limited number of surgeons may offer full-endoscopic techniques to treat LDH [21]. Another limitation may be the hypothetical nature of the DCE as most choice sets in the survey do not represent actual surgical techniques. This, however, might not have influenced the results substantially as most DCE investigations in health contexts have found no evidence of significant hypothetical bias [22]. Also, as the survey was only distributed by the EANS and the CNS, fewer responses were collected from Asia, South America and Africa. It remains up to debate if the inclusion of more respondents from these continents would have affected the results. The continent of employment of the 641 respondents (of which 16\% not from Europe or North America) was not associated with a preference profile. Furthermore, we were not able to calculate a response rate as the survey was distributed by multiple manners by two organizations. For instance, the EANS distributed the survey by email and social media. It is unknown how many non-members were able to see the survey request through social media. Furthermore, some surgeons may be member of both organizations. The amount of respondents $(N=641)$, however, seems to representative for neurosurgeons worldwide and was substantially larger than the prior calculated sample size so that the statistical power would also suffice to address the heterogeneity in preferences. Furthermore, previous research has shown that the response rate of a survey may not be reflective of a survey's quality or bias by itself [23].

The current study is the first to quantify preferences for specifically offering lumbar disk surgery among surgeons. The results of this DCE can help clinicians and policy makers understand why some certain surgical techniques may or may not be offered by surgeons, especially as lumbar discectomy is an elective procedure and multiple techniques are available to treat sciatica. A prior DCE measured preferences of patients for the treatment of low back pain [24]. In this DCE among 348 patients referred to a regional spine center, the majority of the patients prefer nonsurgical interventions to treat their low back pain. In another previously conducted DCE among surgeons, family physicians and patients, the relative importance of presenting symptoms when considering surgery for degenerative lumbar surgery was investigated [25]. Surgeons placed the highest importance on the location of pain such as leg versus back, while patients placed the highest importance on the severity of the pain, walking tolerance and duration of the pain. Similarly, in the current study surgeons gave less importance to the effectiveness on pain or the duration of the (postoperative) pain. These differences in preference profiles between patients and surgeons justify further research to study specific patient preferences for lumbar disk surgery. Such research may further facilitate shared decision making and tailored communication in lumbar disk surgery between patients and surgeons.

\section{Conclusion}

This study shows that surgeons consider the risk of complications as most important when a surgical technique is offered to treat sciatica, while the risk of recurrent disk herniation and effectiveness are also important factors. Surgeons were prepared to trade-off substantial amounts of effectiveness to achieve lower complication rates.

Supplementary Information The online version contains supplementary material available at https://doi.org/10.1007/s00586-021-06838-9. 
Funding not applicable.

Data availability upon request.

\section{Declarations}

Conflicts of interest None of the authors has any potential conflict of interest.

Open Access This article is licensed under a Creative Commons Attribution 4.0 International License, which permits use, sharing, adaptation, distribution and reproduction in any medium or format, as long as you give appropriate credit to the original author(s) and the source, provide a link to the Creative Commons licence, and indicate if changes were made. The images or other third party material in this article are included in the article's Creative Commons licence, unless indicated otherwise in a credit line to the material. If material is not included in the article's Creative Commons licence and your intended use is not permitted by statutory regulation or exceeds the permitted use, you will need to obtain permission directly from the copyright holder. To view a copy of this licence, visit http://creativecommons.org/licenses/by/4.0/.

\section{References}

1. Awad JN, Moskovich R (2006) Lumbar disc herniations: surgical versus nonsurgical treatment. Clin Orthop Relat Res 443:183-197. https://doi.org/10.1097/01.blo.0000198724.54891.3a

2. Jensen RK, Kongsted A, Kjaer P, Koes B (2019) Diagnosis and treatment of sciatica. BMJ 367:16273. https://doi.org/10.1136/bmj. 16273

3. Oppenheim H, Krause F (1909) Uber Einklemmung bzw strangulation der cauda equina. Dtsch Med Wochenschr 35:698-700

4. Caspar W (1977) New operative procedure of lumbar-disk herniation using a microscopic approach thereby causing less tissue injury. Acta Neurochir 36:273-274

5. Yasargil MG (1977) Microsurgical operation of herniated lumbardisk. Acta Neurochir 36:274-275

6. Telfeian AE, Veeravagu A, Oyelese AA, Gokaslan ZL (2016) A brief history of endoscopic spine surgery. Neurosurg Focus 40:E2. https://doi.org/10.3171/2015.11.FOCUS15429

7. Barber SM, Nakhla J, Konakondla S, Fridley JS, Oyelese AA, Gokaslan ZL, Telfeian AE (2019) Outcomes of endoscopic discectomy compared with open microdiscectomy and tubular microdiscectomy for lumbar disc herniations: a meta-analysis. J Neurosurg Spine. https://doi.org/10.3171/2019.6.SPINE19532

8. Gibson JNA, Subramanian AS, Scott CEH (2017) A randomised controlled trial of transforaminal endoscopic discectomy vs. microdiscectomy. Eur Spine J 26:847-856. https://doi.org/10. 1007/s00586-016-4885-6

9. Soekhai V, de Bekker-Grob EW, Ellis AR, Vass C (2018) Discrete choice experiments in health economics: past, present and future. Value Health 21:S325-S325. https://doi.org/10.1016/j.jval.2018. 09.1943

10. Ryan M, Farrar S (2000) Using conjoint analysis to elicit preferences for health care. BMJ 320:1530-1533. https://doi.org/10. 1136/bmj.320.7248.1530

11. Jacobs WC, Arts MP, van Tulder MW, Rubinstein SM, van Middelkoop M, Ostelo RW, Verhagen AP, Koes BW, Peul WC (2012) Surgical techniques for sciatica due to herniated disc, a systematic review. Eur Spine J 21:2232-2251. https://doi.org/10.1007/ s00586-012-2422-9

12. Kamper SJ, Ostelo RW, Rubinstein SM, Nellensteijn JM, Peul WC, Arts MP, van Tulder MW (2014) Minimally invasive surgery for lumbar disc herniation: a systematic review and metaanalysis. Eur Spine J 23:1021-1043. https://doi.org/10.1007/ s00586-013-3161-2

13. Arts MP, Brand R, van den Akker ME, Koes BW, Bartels RH, Peul WC, Leiden-The Hague Spine Intervention Prognostic Study G (2009) Tubular diskectomy vs conventional microdiskectomy for sciatica: a randomized controlled trial. JAMA 302:149-158. https://doi.org/10.1001/jama.2009.972

14. Gadjradj PS, van Tulder MW, Dirven CM, Peul WC, Harhangi BS (2016) Clinical outcomes after percutaneous transforaminal endoscopic discectomy for lumbar disc herniation: a prospective case series. Neurosurg Focus 40:E3. https://doi.org/10.3171/2015. 10.FOCUS15484

15. Reed Johnson F, Lancsar E, Marshall D, Kilambi V, Muhlbacher A, Regier DA, Bresnahan BW, Kanninen B, Bridges JF (2013) Constructing experimental designs for discrete-choice experiments: report of the ISPOR conjoint analysis experimental design good research practices task force. Value Health 16:3-13. https:// doi.org/10.1016/j.jval.2012.08.2223

16. Lancsar E, Louviere J (2008) Conducting discrete choice experiments to inform healthcare decision making: a user's guide. Pharmacoeconomics 26:661-677. https://doi.org/10.2165/00019053200826080-00004

17. de Bekker-Grob EW, Donkers B, Jonker MF, Stolk EA (2015) Sample size requirements for discrete-choice experiments in healthcare: a practical guide. Patient 8:373-384. https://doi.org/ 10.1007/s40271-015-0118-z

18. de Bekker-Grob EW, Rose JM, Donkers B, Essink-Bot ML, Bangma CH, Steyerberg EW (2013) Men's preferences for prostate cancer screening: a discrete choice experiment. $\mathrm{Br} \mathrm{J}$ Cancer 108:533-541. https://doi.org/10.1038/bjc.2013.5

19. Gadjradj PS, Harhangi BS, Amelink J, van Susante J, Kamper S, van Tulder M, Peul WC, Vleggeert-Lankamp C, Rubinstein SM (2020) Percutaneous transforaminal endoscopic discectomy versus open microdiscectomy for lumbar disc herniation: a systematic review and meta-analysis. Spine(Phila Pa 1976). https://doi.org/ 10.1097/BRS.0000000000003843

20. Gadjradj PS, Harhangi BS (2016) Percutaneous transforaminal endoscopic discectomy for lumbar disk herniation. Clin Spine Surg 29:368-371. https://doi.org/10.1097/BSD.0000000000 000366

21. Gadjradj PS, Arts MP, van Tulder MW, Rietdijk WJR, Peul WC, Harhangi BS (2017) Management of symptomatic lumbar disk herniation: an international perspective. Spine(Phila Pa 1976) 42:1826-1834. https://doi.org/10.1097/BRS.0000000000002294

22. de Bekker-Grob EW, Donkers B, Bliemer MCJ, Veldwijk J, Swait JD (2020) Can healthcare choice be predicted using stated preference data? Soc Sci Med 246:112736. https://doi.org/10.1016/j. socscimed.2019.112736

23. Livingston EH, Wislar JS (2012) Minimum response rates for survey research. Arch Surg 147:110. https://doi.org/10.1001/archs urg.2011.2169

24. Klojgaard ME, Manniche C, Pedersen LB, Bech M, Sogaard R (2014) Patient preferences for treatment of low back pain-a discrete choice experiment. Value Health 17:390-396

25. Bederman SS, Mahomed NN, Kreder HJ, McIsaac WJ, Coyte PC, Wright JG (2010) In the eye of the beholder: preferences of patients, family physicians, and surgeons for lumbar spinal surgery. Spine(Phila Pa 1976) 35:108-115. https://doi.org/10.1097/ BRS.0b013e3181b77f2d

Publisher's Note Springer Nature remains neutral with regard to jurisdictional claims in published maps and institutional affiliations. 